\title{
ABERTURA \\ A Revista Acolhendo a Alfabetização em Países de Língua Portuguesa a serviço dos estudos africanos e afro-brasileiros no Brasil
}

\author{
The journal Receiving the literacy in countries of \\ Portuguese language working to African and \\ afro-Brazilian studies in Brazil \\ Dalva GODOY \\ Nilce da SILVA
}

\section{RESUMO}

Este texto apresenta algumas considerações sobre os trabalhos difundidos pela revista eletrônica "Acolhendo a Alfabetização em Países de Língua Portuguesa" a partir de dados coletados em Maputo (Moçambique) no âmbito do edital Pró-África 2007, acerca da educação de jovens e adultos. A perspectiva prático-teórica aqui adotada é a do registro das experiências, para que a escrita possa cristalizar as representações, as práticas bem sucedidas, posicionamentos políticos e militantes no referido país africano. Por meio deste estudo pretende-se colaborar para com a formação de professores e demais interessados no assunto.

Palavras-chave: educação de adultos, formação de professores, Moçambique, memória.

\begin{abstract}
This text intends to present some considerations about the activities of the Journal Receiving the Literacy in countries of Portuguese language, from data collected in Maputo in the scope of the ProAfrica/CNPq Program 2007, concerning adult education. The perspective practical-theoretician adopted here is "the written register" through which we can crystallize the reality, representations, practical successful, positions and militant politicians about this African country. Based on this study, it would like to collaborate with formation of teachers and another interested people who did not had possibility to study African subjects in their school careers.
\end{abstract}

Index Terms: adult education, formation of teachers, Mozambique, memory. 


\section{RÉSUMÉ}

Ce texte présente quelques considération sur les travaux diffusés par "Acolhendo a Alfabetização em Países de língua Portuguesa" à partir de données rassemblées à Maputo (Mozambique) selon la portée "edital Pró Africa CNPS, 2007" au sujet de l'éducation de jeunes et d'adultes.

La perspective pratique et théorique ici adopté est celle du rapport des experiences pour que l'écrit puisse cristalliser les répresentations, les pratiques réussies et les engagements politiques dans ce pays africain. Cette étude vise à collaborer pour la formation des professeurs et d'autres interessés à ce sujet.

Mots Clés: education d'adulte, formation des enseignantes, Mozambique, memoire.

\section{Introdução}

Quando o assunto é alfabetização muitos temas concorrem para o entendimento desse processo. É verdade que em uma sociedade tecnológica as informações escritas estão cada vez mais presentes no dia-a-dia do cidadão desafiando-o a agir e reagir mediante esses dados. Tais conhecimentos vão integrando o legado histórico e cultural de cada povo e podem se transformar em uma nova linguagem por meio da qual seus indivíduos interagem, vivem, pensam e constroem sua história. A linguagem escrita utiliza, a princípio, dos mesmos conhecimentos da linguagem oral, nesse sentido, a língua materna oferece os conhecimentos e algumas das habilidades necessárias à aprendizagem da escrita. A alfabetização em língua portuguesa é assim um desafio para grande parte da população de Moçambique que tem como língua materna outras, diversas e diferentes, línguas que não o português.

No prefácio desse número a professora Nilce da Silva faz um importante relato, a partir de dados coletados em Maputo no âmbito do edital Pro África 2007, sobre as contribuições da Revista Acolhendo a Alfabetização em Língua Portuguesa em relação à educação de jovens e adultos. 
O número 5 da Revista Acolhendo a Alfabetização em Países de Língua Portuguesa nos traz uma significante entrevista com Ernesto Muianga - Director Nacional de Alfabetização e Educação de Adultos em Moçambique, que nos conta um pouco sobre os programas de alfabetização do atual Ministério da Educação e Cultura, suas principais dificuldades na consecução desses programas e seus projetos futuros. Seguindo essa temática poderemos acompanhar o artigo das professoras Nilce da Silva e Aparecida do Carmo Frigeri Berchior: "Fragmentos da Memória: Cultura e língua portuguesa em Maputo: uma homenagem aos irmãos moçambicanos" que recolhe testemunho de alguns moçambicanos, que não têm o português como primeira língua, a respeito de seu processo de aprendizagem em língua portuguesa. Seguindo ainda essa temática poderemos acompanhar o depoimento da professora da Universidade de Eduardo Mondlane (Moçambique) e consultora da Unesco, Agneta Lind, reflexionando sobre as propostas e dificuldades da educação de jovens e adultos em países em vias de desenvolvimento com o tema: "Programa de Alfabetização de adultos: o que podemos esperar?"

O depoimento de Jó António Capece nos relata, com base em uma entrevista com Cristina Daniel Matere Tomo, atual Directora Nacional do Ministério da Educação e Cultura de Moçambique, como os saberes das comunidades locais podem ser apropriados pelo currículo oficial com vistas a construir uma escola inserida na história e cultura do cidadão. Desse ponto de vista podemos entender como é importante o respeito aos saberes da língua materna na constituição dos saberes da escola, sobretudo em um país com inúmeras línguas maternas, mas apenas uma língua oficial.

Tais reflexões podem ser condimentadas com a discussão interessante dos professores Domingos Carlos Buque, de Maputo-Moçambique, Luís Miguel Cardoso, de Viseu-Portugal e das professoras Nilce da Silva, de São Paulo-Brasil e Maria de Jesus Fonseca, de Viseu-Portugal, a respeito do recente acordo ortográfico da escrita da Língua Portuguesa. O artigo “Al- 
guns apontamentos sobre o Acordo Ortográfico: três olhares lusófonos: Brasil, Moçambique e Portugal" apresenta um breve histórico das reformas ortográficas ocorridas na língua portuguesa e constrói, por meio desses três olhares, argumentos prós e contra a unificação da escrita da língua portuguesa. Tal unificação, no entanto, não reflete, necessariamente, a unificação em torno de uma mesma língua oralizada e tem, por conseguinte, repercussões políticas, sociais e educacionais. Com as discussões desse artigo podemos refletir a interface entre linguagem oral e escrita, suas dificuldades e possibilidades. Além disto, curiosamente, observamos a escrita do mesmo artigo nas duas ortografias: a antiga e a atual.

Ao refletir sobre o processo de alfabetização emerge uma discussão calorosa da professora Maria do Rosário Longo Mortatti, da Universidade Estadual Paulista-Brasil, a respeito dos métodos de alfabetização. Em seu artigo "A querela dos métodos de alfabetização no Brasil: contribuições para metodizar o debate" a professora apresenta uma recompilação histórica dos momentos pelos quais passou o país com relação à adoção de diferentes metodologias de alfabetização favorecendo assim a discussão sobre a recente proposta de adoção do método fônico no Brasil. Sua discussão enfatiza a necessidade de não procurar culpados e, sim, a de buscar o diálogo promovendo uma análise que respalde o processo de ensino-aprendizagem.

$\mathrm{Na}$ vertente dos métodos de alfabetização Olívia Leite e José B. Duarte nos brindam com o artigo "Aprender a ler o mundo: adaptação do método de Paulo Freire na alfabetização de crianças" o qual relata o passo a passo de uma pesquisa-ação que buscou soluções para alfabetizar crianças com dificuldades de aprendizagem a partir dos pressupostos da pedagogia Freiriana. Com esse artigo poderemos refletir melhor sobre o lugar dos saberes individuais, já discutidos no artigo de Jó António Capece, enquanto facilitadores dos estímulos para a aprendizagem significativa da linguagem escrita. 
No artigo de Nilce da Silva e Patrícia Claudia da Costa "O aprendizado da língua portuguesa em tempos de modernidade líquida: algumas considerações sobre a aprendizagem da leitura e da escrita de pessoas idosas no Brasil e em Moçambique”, as autoras relatam a experiência de alfabetização com mulheres idosas no Brasil e em Moçambique em que discute a utilização da língua escrita, por esses grupos, em sua função e apreensão como forma de estar e se relacionar com uma sociedade letrada. $\mathrm{O}$ artigo nos leva a refletir sobre as condições de uso da escrita por diferentes grupos em nossa sociedade.

O artigo de Cléa Maria da Silva Ferreira: "Formação de professores à luz da história e cultura afro-brasileira e africana: nova tendência, novos desafios para uma prática reflexiva", discute a necessidade de formação continuada e reflexiva do professor. A autora observa que, em função do estabelecimento da obrigatoriedade do ensino de história e cultura AfroBrasileira e Africana na educação básica brasileira, o professor precisa dar conta de conteúdos até então não contemplados em sua formação inicial e ressalta que a formação do professor em áreas específicas muitas vezes exige desconstrução de certezas, pesquisa e reflexão, além de posicionamentos frente a novos desafios propostos.

No estudo realizado por Dalva Alves, Maria Aznar-Farias e Edwiges Ferreira de Mattos Silvares, apresentado no artigo: "Influência do Treino em Habilidades Sociais na Relação Professor-Aluno: uma contribuição psicopedagógica para professores", com base nos fundamentos da psicologia e da psicopedagogia, as autoras apresentam os resultados de um treinamento com professores, chamam a atenção para as dificuldades comportamentais e emocionais dos alunos no âmbito da sala de aula e discutem o quão importante é incluir o ensino de habilidades sociais nos cursos de capacitação e aperfeiçoamento para professores, bem como incluí-lo como tema a ser trabalhado pela escola, em todos os níveis de ensino, especialmente, desde os anos inicias da formação escolar das crianças. 
Adelto Gonçalves apresenta em "Ficções da memória" a resenha do livro Invenção do Desenho: ficções da memória, de Alberto da Costa e Silva que foi embaixador do Brasil em Portugal (1986-1990), República do Benin e Nigéria.

Finalmente, não há como não percorrer o álbum fotográfico que acompanha este número da Revista Acolhendo. Assim, aliamos palavra e imagem para que possamos compreender um pouco mais acerca da realidade moçambicana, em especial, da capital, Maputo.

Como vêem esse número 5 da Revista se propõe a apresentar e a discutir questões relativas à aprendizagem da língua escrita no Brasil e em Moçambique ressaltando suas dificuldades específicas, sua interface com a linguagem oral e a necessidade de construí-la como mais uma forma de linguagem e como instrumento de mediação entre pessoas e conhecimentos. Que a leitura seja profícua!

\section{Prefácio}

A memória do indivíduo depende de seu relacionamento com a família, com a classe social, com a escola, com a Igreja, com a profissão; enfim, com os grupos de convívio e os grupos de referência peculiares a esse indivíduo

(Ecléa Bosi, 1994, p. 54)

Sabemos que às revistas, não cabem prefácios. Entretanto, gostaríamos de esclarecer ao leitor a importância e especificidade dos números 5 e 6 da Revista Acolhendo a Alfabetização em Países de Língua Portuguesa que apresentarão, majoritariamente, material bibliográfico e fotográfico, fruto do trabalho de pesquisa realizado no âmbito do Edital Pro-África 2007, fase 2, que teve como objeto de estudo práticas de excelência no âmbito da alfabetização de jovens e adultos em Moçambique, mais especificamente em Maputo e seus arredores para que pudéssemos elaborar, assim, subsídios prático-teóricos que constituem corpus prático-teóricos, subsídio para a viabili- 
dade da Lei 10639/03 ${ }^{1}$ que altera a Lei 9394/96 de Diretrizes e Bases da Educação Nacional que estabelece obrigatoriedade do Ensino de História e Cultura Afro-Brasileira e Africana na Educação Básica e o Parecer No 1/04 do CNE que estabelece as Diretrizes Curriculares das Relações ÉtnicoRaciais.

Neste contexto, os respectivos números da Revista Acolhendo procuram oferecer material para as diferentes modalidades de atualização continuada para educadores, tanto para repertório informativo específico como para formação de excelência na matéria e colocar em diálogo entre as duas sociedades, a brasileira e a moçambicana, dilaceradas até as raízes pelas mais cruéis desigualdades. Observemos alguns dados:

De acordo com fontes oficiais da República de Moçambique, este território está localizado na costa oriental da África Austral e tem como províncias: Cabo Delgado, Niassa, Nampula, Tete, Zambézia, Manica, Sofala, Inhambane, Gaza e Maputo Província e Maputo Cidade. Tem como presidente da República o senhor Armando Guebuza. A área deste país é de $799.390 \mathrm{~km}^{2}$ e, de acordo com dados oficiais de 2006 , sua população é de 19.888.701. Sua capital é Maputo, a moeda é o metical e a língua oficial é o Português.

Ao longo dos tempos, Moçambique tem sido ocupado por muitos povos, apresentado um enorme mosaico de indivíduos de diferentes origens e culturas: africanos (negros e mestiços), árabes, indianos, europeus, dentre outros.

Atualmente, os povos que habitam este país pertencem ao grande grupo dos Bantu que possui inúmeras etnias. Vejamos algumas delas em Moçambique: A) Suahilis: ocupam majoritariamente locais costeiros entre

\footnotetext{
${ }^{1}$ Esta legislação foi atualizada por meio da Lei 11.645, de 10 de março de 2008, DOU 11.03.2008 e alterou a Lei $n^{\circ}$ 9.394, de 20 de dezembro de 1996, modificada pela Lei $n^{\circ} 10.639$, de 9 de janeiro de 2003, que estabelece as diretrizes e bases da educação nacional, para incluir no currículo oficial da rede de ensino a obrigatoriedade da temática "História e Cultura Afro-Brasileira e Indígena". Em seu texto, foi inserido também o ensino da cultura indígena no país.
} 
Quionga e Quelimane e pertencem, em sua maioria, ao Islamismo. B) Macuas-Lomués: formam a mais numerosa etnia do país, porém, com enorme subdivisão. C) Macondes: localizam-se no seu planalto ao sul do Rovuma, recusam, em sua maioria, qualquer forma de colonização ou influência estrangeira. D) Ajauas: são principalmente agricultores e artífices islâmicos. Estas quatro etnias resistiram bravamente à colonização portuguesa. Além destas quatro etnias, encontram-se, no norte do país, os Nhanjas e Angonis.

No eixo zambeziano, há ainda um grupo numeroso e vasto com diferentes etnias. A saber: Maraves, Chonas, Macuas-Lomués, Suahilis, Portugueses, Indianos, Senas e os Chuabos.

Acrescenta-se ainda, a Norte de Tete, os Maraves orientais e os Angonis, quase na fronteira do Malawi.

Já, ao sul do Zambese, temos: os Chonas (que entraram em primeiro lugar com os portugueses no século XVI); os Angonis; os Tsongas; os Chopes (que ofereceram muitos migrantes para a África do Sul); os Bitongas.

E finalmente, para que este quadro fique completo, há que se destacar a presença dos asiáticos, mais precisamente, dos indianos.

No século XIX e XX, milhares de moçambicanos foram "exportados" para Cuba, para o trabalho no Canal de Suez, para o Transval e o Natal, na África do Sul, assim como, para o Zimbabwe.

Esta corrente de migração forçada trazia lucro para o governo português, pois, após uma série de acordos, o Governo recebia uma quantidade de dinheiro por "unidade" de moçambicano enviado. Assim, em troca de um salário maior e com o apoio do Estado Português, estes imigrantes encontraram e ainda se encontram em trabalhos domésticos e nas minas, com elevada periculosidade e taxa de mortalidade.

De acordo com Smulders (2001), a partir de 1972, com a declaração da independência de Moçambique de Portugal, até 1992, com a celebração de acordo de paz entre a Frente de Libertação de Moçambique (Frelimo) e a Renovação Nacional Moçambicana (Renamo), Moçambique enfrentou por 
20 anos uma Guerra Civil que apresenta o seguinte saldo: uma nação devastada com um milhão de mortos; milhares de minas terrestres, que continuam matando e mutilando civis e dificultando a agricultura; 1,7 milhão de refugiados, que, em 1996, voltam para seu país; uma das menores rendas per capita do mundo - apenas US\$ 80 em 1996; 80\% dos seus habitantes na prática da agricultura de subsistência; grande evasão de mão-de-obra qualificada; miséria generalizada; alta incidência de tifo e cólera; 17 milhões de pessoas em situação de dificuldade de comunicação; o índice de desenvolvimento humano na posição 168 de 174 países; e, pelo menos, mais de 21 línguas locais, sendo que apenas uma pequena parcela da população tem a língua portuguesa como materna, em torno de $6,5 \%$.

Tendo em vista esta situação, trataremos a seguir, do último dos dados apresentados acima: a baixa porcentagem da população que tem a Língua Portuguesa como materna.

De acordo com Gonçalves (2006), apesar da baixa porcentagem destacada acima, Moçambique tem a Língua Portuguesa como oficial, sendo falada essencialmente como língua segunda por uma pequena parte da sua população ter o domínio desta significa hoje a obtenção de prestígio social, da obtenção de benefícios sociais e econômicos. Porém, foram ocupados diferentes status pela mesma desde o ano de 1498, ano da chegada de Vasco da Gama em Moçambique.

Nesta direção, de acordo com a professora Débora Nandja da Universidade Eduardo Mondlane (2006), a forma como foi conduzido o processo de colonização não possibilitou que a Língua Portuguesa se tornasse hegemônica de modo que esta língua se torna um efetivo meio de comunicação para algumas camadas da população moçambicana somente após a independência do país. De acordo com Valkoff (1966), o Português começou a tornar-se uma língua franca na costa ocidental de África na segunda metade do século XV, e, no século XVII, estava no seu auge na chamada "aze do Cabo" (África do Sul). No século XVIII, começa a dar gradualmente lugar a 
outras línguas, tornando-se uma "língua moribunda" nesta região no século XIX. No que diz mais particularmente respeito a Moçambique, Newitt (1998) refere que durante os séculos XVI e XVII, a presença portuguesa se fez sentir no litoral de Moçambique, assim como ao longo do vale do Zambeze, em Sofala e Tete, sobretudo através da actividade comercial, o principal motor dos contactos estabelecidos entre os portugueses e a população local. Embora não se disponha de informação documentada sobre o papel que o Português desempenhava neste intercâmbio, sabe-se que a presença portuguesa trouxe poucas mudanças fundamentais na estrutura social local (NEWITT, 1998), sendo pouco provável que tenham chegado a surgir nesta época focos importantes de uso desta língua.

Vale ressaltar também que uma das dificuldades da penetração dos portugueses no território Moçambicano foi a resistência diante da língua do colonizador por diferentes etnias locais, especialmente árabes e muçulmanas que, na verdade, rejeitavam a cultura portuguesa e o catolicismo, marca registrada da mesma.

Interessante salientar, para os fins deste artigo, outros dados apontados por Gonçalves (2006), que apenas no século XVIII (1752), a administração de Moçambique deixa de depender da Índia e começa a ser dominada pelos portugueses, e por isso, apenas uma escola primária dedicada ao ensino da Língua Portuguesa existia até 1890.

A partir de então, Portugal decide finalmente ocupar Moçambique efetivamente e como conseqüência difundir a Língua Portuguesa seja por meio de escolas, ou por meio da chegada de milhares de colonos portugueses no país. Finalmente, com a independência do país, a opção pela Língua Portuguesa como oficial fez com que aumentasse significativamente os alunos em situação de aprendizagem da mesma: após a independência do país, ocorrida em 1975, via-se o domínio da língua portuguesa como estratégia emancipatória, forte instrumento contra "regionalismos" e "racismos" (CACCIA-BAVA; THOMAZ, 2001). 
Tais fatores históricos juntos formaram a atual comunidade de falantes de Português nas suas variedades moçambicanas em uso nos dias de hoje: este continuиm é composto por diversas subvariedades que oscilam entre um extremo muito próximo do padrão europeu, e um extremo "basilectal".

Contudo, conforme ressaltamos anteriormente, hoje o português é a língua de menos de $10 \%$ da população moçambicana.

No que diz respeito especificamente à Educação de Jovens e Adultos, de acordo com Mário e Nandja (2006), ambos da Faculdade de Educação da Universidade Eduardo Mondlane, três etapas distintas na provisão de programas desta modalidade de ensino: a primeira etapa começa em 1975, após a proclamação da independência nacional, e estende-se até meados da década de 80, período em que foram realizadas sucessivas campanhas de alfabetização e educação de adultos em todo o território nacional. Já na segunda etapa, do início dos anos de 1980 até 1995, há uma redução de atividades na área da alfabetização de jovens e adultos, devido, segundo os citados autores, à intensificação da guerra de desestabilização então movida pelo regime do apartheid da África do Sul. Para além da destruição de infraestruturas e perda de vidas humanas, a guerra esteve na origem direta do afluxo de milhares de refugiados moçambicanos nos países vizinhos e de milhões de deslocados em todo o país. Assim, a alfabetização e educação de adultos passaram a estar confinadas às grandes cidades. A única exceção foi a iniciativa de organizações não-governamentais, religiosas e de indivíduos que mantiveram os programas em pequena escala, tendo produzido, em muitos casos, programas inovadores, como a alfabetização com base em línguas locais. Finalmente, a última etapa começa em 1995 e estende-se até os nossos dias e para Mário e Nandja (2006), é caracterizada por uma redescoberta e pelo resgate desta modalidade de ensino, constando com o apoio de vários instrumentos legais, inclusive decorrentes da própria Constituição da República, o que demonstra, tanto por parte do governo, como da sociedade, vontade de conferir à alfabetização um espaço e um papel cada vez 
mais ativo na redução da pobreza e no desenvolvimento do país, conformando-se, assim, com os compromissos.

Em 1999, o Movimento de Educação para Todos de Moçambique (MEPT), que integra mais de 70 membros, incluindo Organizações NãoGovernamentais, Instituições Religiosas e Sindicatos que pretende atingir os seguintes objetivos: propiciar à sociedade civil condições de participar no processo de alfabetização de jovens e adultos no país e promover a alfabetização sem discriminação de idade e gênero.

Neste contexto, tanto para fins deste artigo, como para fins da continuidade da cooperação bilateral em questão, é importante conhecermos a definição de "alfabetização", apontada pelos professores da Faculdade de Educação da Universidade Eduardo Mondlane em que eles afirmam que a alfabetização é considerada, por um lado, a aquisição de noções básicas de leitura, escrita e cálculo e, por outro lado, um processo que estimula a participação nas atividades sociais, políticas, permitindo educação contínua e permanente.

Entretanto, ressaltam os autores em questão, muito pouco tem sido feito para que estes objetivos sejam alcançados, e ainda, para corroborar com esta situação, a Conferência do Milênio da ONU de 2000, a alfabetização de jovens e adultos não foi considerada como um objetivo da mesma, excluindo esta modalidade de ensino totalmente, provavelmente por tratarse de uma população desprestigiada e, conseqüentemente, menosprezada no âmbito do sistema educacional.

Apesar das adversidades encontradas em Moçambique, Mário e Nandja (2005) destacam a redução do analfabetismo no país, sobretudo entre as mulheres. E ainda que após o lançamento da Década da Literacia em 2003 pela ONU, alguma perspectiva e alento foram encontrados tanto para as ações do Governo como das ONGs. Deste modo, a partir da expansão das instituições dedicadas à alfabetização de jovens e adultos, faz-se mister res- 
gatar e registrar a memória social do contexto moçambicano, processo este que não tem sido feito pelos motivos sócio-históricos acima mencionados.

Não obstante o progresso alcançado na redução das taxas globais de analfabetismo, quando comparadas as taxas entre homens e mulheres (24 pontos percentuais em 1996 para 31 pontos percentuais em 2004), nota-se que o fosso continua a aumentar, tanto na cidade como nas zonas rurais.

Além deste problema, os autores em questão citam também: as elevadas taxas de desistência nos cursos de alfabetização de jovens e adultos, e conforme já assinalara Perpétua Gonçalves — e nós destacamos neste artigo, ainda que brevemente - a grande maioria dos jovens e adultos não domina a Língua Portuguesa.

Diante deste quadro, elaborou-se uma proposta chamada "Projecto de Educação de Mulheres" que selecionou, além da Língua Portuguesa, outras línguas usadas em Moçambique para que a alfabetização de jovens e adultos se desse em ambas as línguas. Foram selecionadas: duas línguas do norte (emakhwa e nyandja), duas do centro (sena e ndau) e uma do sul do país (changana), e diante desta proposta, a produção de material didático que a satisfizesse. Infelizmente a referida proposta não se efetivou, tendo em vista o pouco investimento governamental nesta modalidade e proposta de ensino.

Em suma, apesar da expansão das instituições dedicadas à alfabetização de jovens e adultos, muito ainda deve ser feito neste setor tendo em vista as questões aqui apontadas decorrentes da composição étnica do país; das características da colonização portuguesa até o século XIX - marcada pelo distanciamento da colônia; pela natureza da colonização portuguesa no século $\mathrm{X}$ que esvaziou o país de seus habitantes, forçando-os à migração; a opção pela Língua na Independência e o período de pós-independência, com suas fases apontadas por Mário e Nandja, tal como apresentamos aqui.

Frente à situação aqui exposta, há que se destacar o conceito de diversidade cultural, pois tal qual o no caso brasileiro, a cultura moçambicana 
possui múltiplas dimensões advindas da sua própria história e estas devem ser levadas em consideração quando tratamos de Educação e, neste caso, especificamente, da Educação de Jovens e Adultos.

Neste sentido, apesar da influência marcante portuguesa, de acordo com os dados obtidos por meio da parceria Faculdade de Educação Universidade de São Paulo e Faculdade de Educação Universidade Eduardo Mondlane, não apagou as culturas já existentes em Moçambique. Acreditamos que é o sistema educacional e ou as iniciativas das ONGs que necessitam aprender a conviver de fato com esta realidade multiétnica e, portanto, multicultural.

Do nosso ponto de vista, há que se resgatar a história destas culturas em questão, não de forma folclórica, e evitar, a todo o custo, uma educação eurocentrada e a omissão dos atores destas culturas.

Em suma, este número da Revista Acolhendo é dedicado às "memórias"2 do povo moçambicano, além de dialogar com outros artigos escritos por portugueses, brasileiros aqui presentes, no sentido de que, por meio da escrita, consigamos despertar postura reflexiva e investigativa dos nossos leitores, potencializando-os para a busca constante de novas aprendizagens e compreensões; pautadas em uma formação de professores e ou alunos numa perspectiva contextualizada e reflexiva; dirigidas para a recontextualização do conhecimento na e para a prática do professor; apoiadas nos princípios que privilegiavam o processo de construção do conhecimento; norteadas pela articulação entre a teoria e a prática, a ação e a reflexão, o ensino e a aprendizagem, a razão e a emoção, o individual e o coletivo; e, realizadas por professores e alunos em um processo contínuo de investigação, interação, cooperação e socialização, indicando a ocorrência das mudanças gestadas nos espaços sócio-educativos; relacionadas às políticas públicas articu-

\footnotetext{
${ }^{2}$ Agradeço imensamente aos professores da Faculdade de Educação da Universidade Eduardo Mondlane; aos profissionais da Diretoria Nacional de Educação de Jovens e Adultos; ao senhor Armindo Macue e tantos outros moçambicanos que se dispuseram, mui gentilmente, a partilhar suas histórias conosco.
} 
ladas com as diretrizes educacionais nacionais brasileiras ou moçambicanas; que oferecem condições de planejamento para continuidade e ampliação; que são referência na localidade (citados por colegas, ex-colegas, alunos, dentre outros atores sociais).

Esperamos que, desta forma, por meio da construção deste registro escrito, tenhamos materializado as práticas e representações de professores e alunos envolvidos com a alfabetização de jovens e adultos em Moçambique, mais especificamente em Maputo e seus arredores. E, na mesma direção, tenha contribuído para com a afirmação da cidadania brasileira e moçambicana já que estas se associam à preservação da memória social na medida em que tais elementos poderão oferecer subsídios ao cidadão e ao agente social sobre o conjunto de saberes que vêm sendo acumulados em decorrência de ações e estratégias produzidas historicamente. Sempre, com a intenção de promover a reconstituição da identidade individual e social, permitindo-lhe o re-conhecimento.

Finalmente, adiantamos aos nossos leitores que o n. 6 desta revista, previsto para março de 2009 , tratará de apresentar o material que temos coletado junto a professores em formação e interessados ${ }^{3}$ sobre as culturas africanas e afro-brasileiras sobre o conhecimento prévio destes acerca da História e Cultura Afro-Brasileira e verificar até que ponto este saber é folclorizado ou estereotipado. Queremos colaborar também com possibilidades de efetiva constituição de espaços para formação de professores e colaborar para a compreensão de alguns desafios na formação inicial de professores à luz da temática História e Cultura Afro-Brasileira e Africana em São Paulo, além de analisar como as fronteiras raciais e étnicas dialogam em termos da formação em serviço oferecida aos professores no âmbito desta pesquisa e a prática dos mesmos em sala de aula, para que ocorra a possibilidade da discussão do mito da igualdade racial difundido na sociedade brasileira.

\footnotetext{
${ }^{3}$ Dois grupos de professores e interessados na temática desenvolveram estudos sistemáticos, por meio de 15 encontros de quatro horas de duração cada um durante o primeiro semestre de 2008.
} 


\section{Referências bibliográficas}

BOSI, Ecléa (1994). Memória e sociedade: lembranças de velhos. São Paulo: Companhia das Letras.

CACCIA-BAVA, Emiliano de Castro; THOMAZ, Omar Ribeiro (2001). Moçambique em movimento: dados quantitativos. In: FRY, Peter (Org.). Moçambique: ensaios. Rio de Janeiro: UFRJ.

GONÇALVES, Perpétua. (Dados para a) História da Língua Portuguesa. Disponível em: <http://www.instituto-camoes.pt/cvc/idiomatico/05/02. html>. Acesso em: 3 maio 2006.

MÁRIO, Mouzinho; NANDJA, Débora. Desafios da Educação para Todos. Paris: EFA Global Monitoring; Unesco, 2006.

MUNANGA, Kabengele (Org.). Lei 10.639/03: depoimento [São Paulo: fev. 2005]. Entrevistador: Fábio de Castro. Disponível em: <http://www.re portersocial.com.br/entrevista.asp?id=60>. Acesso em: 13 ago. 2005.

NEWITT, Malyn (1998). O impacto dos portugueses no comércio, política e estruturas de parentesco da África Oriental no século XVI. Oceanos, Revista Trimestral da CNCDP, Lisboa, abr./jun. 1998, 34, p. 62-72.

SMULDERS, M. J. The challenge of Adult Education at the Eduardo Mondlane University: a needs assessment to implement a curriculum in Adult Education at the MEU. Groningen: May 2001.

\section{AUTORAS}

\section{Nilce da Silva}

Professora Doutora da Faculdade de Educação da Universidade de São Paulo - Brasil e-mail: nilce@usp.br

\section{Dalva Godoy}

Professora da Universidade do Estado de Santa Catarina - Brasil e-mail: dalvagodoy@gmail.com 


\section{Como citar este artigo:}

SILVA, Nilce da e GODOY, Dalva. A Revista Acolhendo a Alfabetização em Países de Língua Portuguesa a serviço dos estudos africanos e afrobrasileiros no Brasil. Revista ACOALFAplp: Acolhendo a Alfabetização nos Países de Língua portuguesa, São Paulo, ano 3, n. 5, 2008. Disponível em: <http://www.acoalfaplp.net>. Publicado em: setembro 2008.

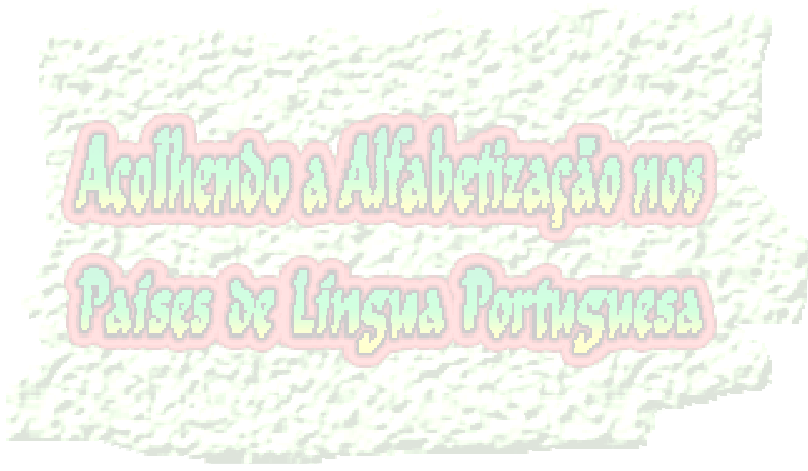

Sede da Edição: Faculdade de Educação da Universidade de São Paulo - Av da Universidade, 308 - Bloco A, sala 111 - São Paulo - SP - Brasil - CEP 05508-040. Grupo de pesquisa: Acolhendo Alunos em situação de exclusão social e escolar: o papel da instituição escolar. 